\title{
Prevalence and factors associated with modern contraceptives utilization among female adolescents in Uganda
}

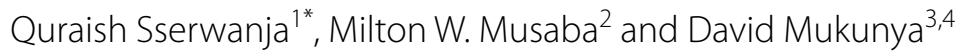

\begin{abstract}
Background: The sexual and reproductive health (SRH) needs of adolescents remain largely unmet. For instance, over 20 million female adolescents in need of, a modern contraceptive method are not using any. This study determined the factors associated with utilization of modern contraceptives among female adolescents in Uganda.

Methods: A cross sectional study was conducted using the Uganda Demographic and Health Survey (UDHS) 2016 data of 4, 264 adolescents aged 15 to 19 years. Multistage stratified sampling was used to select study participants. Multivariable logistic regression was used to determine the factors associated with modern contraceptive utilization. All our analyses were done using SPSS version 25.

Results: The prevalence of modern contraceptive utilization among female adolescents was 9.4\% (401/4264: (95\% $\mathrm{Cl}$ : 8.6-10.3). The odds of contraceptive utilisation were 1.6 times ( $\mathrm{AOR}=1.60 ; 95 \% \mathrm{Cl}: 1.09-2.34$ ) higher among married adolescents compared to unmarried adolescents. Adolescents whose age at first birth was less than 15 years ( $\mathrm{AOR}=2.01 ; 95 \% \mathrm{Cl}: 1.01-3.99)$ were twice more likely to utilize a modern contraceptive compared to those whose age at first birth was above 15 years. Women belonging to the Central region ( $\mathrm{AOR}=1.93 ; 95 \% \mathrm{Cl}: 1.01-3.69$ ) and those in the middle wealth quintile ( $\mathrm{AOR}=1.91 ; 95 \% \mathrm{Cl}$ : 1.06-3.46) were $93 \%$ and $91 \%$ more likely to utilize a modern contraceptive compared to those in the Northern region and those in the poorest wealth index respectively.
\end{abstract}

Conclusion: The prevalence of modern contraceptive utilization was $9.4 \%$. The findings show the need for designing targeted interventions due to differences in adolescents according to their wealth index, regions and marital status.

Keywords: Adolescents, Contraceptives, Utilization, Uganda

\section{Background}

Adolescence is a crucial period during which many begin sexual activity $[1,2]$. Globally, the sexual and reproductive health $(\mathrm{SRH})$ needs of adolescents have remained largely unmet with about 20 million female adolescents aged 15-19 years in need of modern contraceptive methods [3]. Sub-Saharan Africa has the highest rates of adolescent pregnancy and the lowest utilization of modern

\footnotetext{
*Correspondence: qura661@gmail.com

1 Monitoring and Evaluation Department, Doctors With Africa, CUAMM,

TM Lion Hotel, Juba, South Sudan

Full list of author information is available at the end of the article
}

contraceptives $[1,2,4]$. A third of adolescent pregnancies in Sub-Saharan Africa are unintended, with over a third of these unintended pregnancies being unwanted and end up as unsafe terminations [1, 4]. Pregnancy and childbirth related complications are the leading causes of maternal death among female adolescents aged 15-19 in low and middle-income countries (LMICs) [5, 6]. Adolescent pregnancy and childbirth is associated with other poor health outcomes such as anemia, preterm birth, low birthweight, adverse adolescent mental health effects, besides its negative effects on higher education attainment and job opportunities [1, 2, 7-10]. 
Use of modern contraceptives reduces maternal mortality, improves health outcomes of adolescent mothers and their children and reduces the costs associated with teenage pregnancy $[5,11]$. Planned childbirths increase the likelihood of attaining higher educational levels, which results in financial independence [12-14]. Despite the global progress in increasing availability and coverage of family planning services, $[5,15]$ most of the contraceptive needs of adolescents are largely unmet [1, $5,11]$. Uganda's adolescent fertility rates are among the highest in the world $[13,16,17]$. According to the latest Uganda Demographic and Health Survey (DHS), 24.8\% of girls aged 15-19 had already begun childbearing [18]. Furthermore, Uganda has one of the lowest contraceptive prevalence rate in the region [16]. The high numbers of adolescents giving birth at an early age partly contributes to Uganda's high fertility levels [19].

The Government of Uganda through the ministry of Health and its development partners have come up with different initiatives to ensure improved distribution, access and utilization of contraceptives, however, the contraceptive prevalence rate remains low while the unmet need is high $[13,20]$. Studies in Uganda have focused mainly on knowledge, attitudes and barriers to access among older women and others have been predominantly qualitative in nature [13]. For Uganda's health system to effectively respond to the high and increasing population of adolescents, its crucial to understand the predictors of modern contraceptive utilization among female adolescents. This study aimed at describing factors associated with utilization of modern contraceptives among female adolescents aged 15-19 years. Its recommendations will help in improving implementation of programs focusing on the reproductive health needs of female adolescents in Uganda, which with better health, this will increase their contribution to the development of the country.

\section{Material and methods}

\section{Study design}

We conducted a secondary data analysis of the 2016 Uganda demographic health survey (UDHS) data set.

\section{Study data}

We used the 2016 Uganda Demographic and Health Survey (UDHS) dataset for this study after obtaining permission from the MEASURE DHS project. MEASURE DHS program conducts periodical nationally representative cross-sectional household surveys in low and middle income countries (LMICs) standardized to enable comparisons among the different countries [21]. The surveys are usually conducted after every five years [21].
The UDHS data were collected from June to December 2016 [22]. UDHS was implemented by the Uganda Bureau of Statistics (UBOS) with the technical assistance of Inner City Fund (ICF) International through the USAID-supported MEASURE DHS project [22]. The UDHS inquired about household members' and individuals' socio-demographic and reproductive health information using household, women's, men's and biomarker questionnaires $[22,23]$. The data used in this study was collected using the women's questionnaire. Female adolescents were asked if they were currently using any method of modern contraception [22].

\section{Study sampling and participants}

The UDHS used two-stage systematic sampling to select participants from households nested in clusters (enumeration areas) across the all the regions of Uganda $[22,23]$. The 2014 population and housing census sample frame was used to select the enumeration areas [22]. UDHS 2016 included women aged 15 to 49 years who were either permanent residents or slept in the selected household the night before the survey [22]. In this study, we included female adolescents aged 15-19 years who responded to the women's questionnaire. The UDHS interviewed 18,506 women aged 15-49 years after administering informed consent [22]. Of the 18,506 women, 4,264 were female adolescents aged between 15 and 19 years [22].

\section{Outcome variables}

Utilization of any method of modern contraceptive method was coded as one (1) while non-utilization was coded as zero $(0)$.

\section{Explanatory variables}

This study included determinants of modern contraceptives utilization basing on evidence from available literature and data $[3,13,19,22]$. Nine explanatory variables were included in the analysis as shown in Additional file 1: Table 1. Wealth index is a measure of relative household economic status and was calculated by DHS from information on household asset ownership using Principal Component [22].

\section{Statistical analysis}

To ensure validity of our study findings, sampling weights provided by UDHS were used. Use of sample weights helped to account for the unequal probability sampling in different strata [24] and to ensure representativeness of the survey results at the national and regional level [25]. We used Complex sample analysis was performed using SPSS version 25.0 statistical software to account for the multi-stage cluster study design. Proportions were 
tabulated for each of the categorical independent variable. Each exposure was assessed separately for its association with the outcome variable using bivariable logistic regression and we presented crude odds ratio (COR), $95 \%$ confidence interval $(\mathrm{CI})$ and $\mathrm{p}$-values. Independent variables found significant at bivariable level ( $\mathrm{p}$-value $<0.25$ ) and those found significant in similar context studies were included in the final multivariable logistic regression model. Adjusted odds ratios (AOR), 95\% Confidence Intervals $(\mathrm{CI})$ and p-values were calculated with statistical significance level set at $p$ value $<0.05$. All variables in the model were assessed for collinearity, which was considered present if the variables had a variance inflation factor (VIF) greater than 10.

\section{Results}

\section{Sociodemographic characteristics of Study Participants}

A total of 4,264 women were included in this study (Table 1). Of these, 401 (9.4\%) (95\% CI: 8.6-10.3) were utilizing a modern contraceptive. Majority of the adolescents were residing in rural areas (75.7\%), aged 15-17 years $(61.6 \%)$, not married $(80.1 \%)$, had seven or less years (primary) of education (64.7\%) and belonged to the richest wealth quintile (23.2\%).

Factors associated with modern contraceptive utilization

Factors associated with modern contraceptive utilization were: marital status, age at first birth, region and wealth index as indicated in Table 2.

Married adolescents $(\mathrm{AOR}=1.60 ; 95 \%$ CI: 1.09 2.34 ) were $60 \%$ more likely to utilize a modern contraceptive compared to non-married adolescents. Adolescents whose age at first birth was less than 15 years $(\mathrm{AOR}=2.01 ; 95 \% \mathrm{CI}: 1.01-3.99)$ were twice as likely to utilize a modern contraceptive compared to those whose age at first birth between was 15-19 years. Women belonging to the Central region $(\mathrm{AOR}=1.93$; 95\% CI: $1.01-3.69)$ were $93 \%$ more likely to utilize a modern contraceptive compared to those in the Northern region. Women belonging to the middle wealth quintile $(\mathrm{AOR}=1.91 ; 95 \% \mathrm{CI}: 1.06-3.46)$ were $91 \%$ more likely to utilize a modern contraceptive compared to those in the poorest wealth index.

\section{Discussion}

This study investigated the prevalence and factors associated with modern contraceptive utilization among Ugandan female adolescents aged 15-19 years. Prevalence of modern contraceptive utilization was $9.4 \%$ (95\% CI: 8.6-10.3). This is very low and negatively affects Uganda's progress of achieving sustainable development goal (SDG) 3 target 3.7 aimed at ensuring
Table 1 Background characteristics of Ugandan female adolescents as per the 2016 UDHS

\begin{tabular}{|c|c|c|c|c|}
\hline Characteristics & & $N=4264$ & & $\%$ \\
\hline \multicolumn{5}{|l|}{ Age } \\
\hline 15 to 17 & & 2629 & & 61.6 \\
\hline 18 to 19 & & 1636 & & 38.4 \\
\hline \multicolumn{5}{|l|}{ Residence } \\
\hline Urban & & 1034 & & 24.3 \\
\hline Rural & & 3230 & & 75.7 \\
\hline \multicolumn{5}{|l|}{ Region } \\
\hline Western & & 982 & & 23.0 \\
\hline Eastern & & 1248 & & 29.3 \\
\hline Central & & 1132 & & 26.6 \\
\hline Northern & & 902 & & 21.2 \\
\hline \multicolumn{5}{|l|}{ Age at First Birth ${ }^{\mathrm{a}}$} \\
\hline Less than 15 & & 53 & & 01.2 \\
\hline 15-19 & & 773 & & 18.1 \\
\hline \multicolumn{5}{|c|}{ FP Counselling in the year } \\
\hline Yes & & 514 & & 12.1 \\
\hline No & & 3750 & & 87.9 \\
\hline \multicolumn{5}{|l|}{ Marital status } \\
\hline Married & & 850 & & 19.9 \\
\hline Not Married & & 3414 & & 80.1 \\
\hline \multicolumn{5}{|l|}{ Working } \\
\hline Yes & 2059 & & 48.3 & \\
\hline No & 2205 & & 51.7 & \\
\hline \multicolumn{5}{|l|}{ Education level } \\
\hline No Education & & 76 & & 01.8 \\
\hline Primary Education & & 2759 & & 64.7 \\
\hline Secondary Education & & 1351 & & 31.7 \\
\hline Higher & & 78 & & 01.8 \\
\hline \multicolumn{5}{|l|}{ Wealth Index } \\
\hline Poorest & & 764 & & 17.9 \\
\hline Poorer & & 840 & & 19.7 \\
\hline Middle & & 815 & & 19.1 \\
\hline Richer & & 854 & & 20.0 \\
\hline Richest & & 990 & & 23.2 \\
\hline \multicolumn{5}{|c|}{ Modern contraception use } \\
\hline Yes & & 401 & & 09.4 \\
\hline No & & 3863 & & 90.6 \\
\hline
\end{tabular}

a Age at birth not applicable to 3438

universal access to sexual and reproductive health-care services, including for family planning by 2030 [26]. With low contraceptive utilization, and with Uganda having some of the highest adolescent fertility rates in the region, these findings imply that a lot has to be done to ensure increased access and utilization of contraceptives as one of the ways of reducing teenage pregnancies and the associated morbidity and mortality if we are to meet the SDG targets as a country. 
Table 2 Predictors of modern contraception use among female Ugandan adolescents

\begin{tabular}{|c|c|c|c|c|}
\hline Characteristics & $\begin{array}{l}\text { Crude model }(n=4264) \\
\text { COR }(95 \% \mathrm{Cl})\end{array}$ & $P$ value & $\begin{array}{l}\text { Adjusted odds ratio }(n=4264) \\
\text { AOR }(95 \% \mathrm{Cl})\end{array}$ & $P$ value \\
\hline \multicolumn{5}{|l|}{ Age } \\
\hline 15 to 17 & 1 & $<0.001$ & 1 & 0.468 \\
\hline 18 to 19 & $4.18(3.18-5.49)$ & & $1.19(0.74-1.90)$ & \\
\hline \multicolumn{5}{|l|}{ Education level } \\
\hline No education & 1 & 0.008 & 1 & 0.386 \\
\hline Primary & $2.14(0.74-6.18)$ & & $1.75(0.55-5.53)$ & \\
\hline Secondary & $2.97(0.99-2.19)$ & & $2.45(0.72-8.32)$ & \\
\hline Higher & $5.58(1.57-19.86)$ & & $2.25(0.16-2.23)$ & \\
\hline Marital Status & & & & 0.016 \\
\hline No & 1 & $<0.001$ & 1 & \\
\hline Yes & $3.69(2.84-4.79)$ & & $1.60(1.09-2.34)$ & \\
\hline \multicolumn{5}{|l|}{ Region } \\
\hline Northern & 1 & 0.001 & 1 & 0.386 \\
\hline Eastern & $1.69(1.18-2.43)$ & & $0.97(0.55-1.72)$ & \\
\hline Western & $1.22(0.79-1.89)$ & & $1.16(0.62-2.18)$ & \\
\hline Central & $2.19(1.46-3.28)$ & & $1.93(1.01-3.69)$ & \\
\hline \multicolumn{5}{|l|}{ FP counselling } \\
\hline No & 1 & $<0.001$ & 1 & 0.350 \\
\hline Yes & $3.04(2.24-4.12$ & & $1.19(0.82-1.73)$ & \\
\hline Wealth Index & & & & 0.242 \\
\hline Poorest & 1 & 0.308 & 1 & \\
\hline Poorer & $1.36(0.89-2.06)$ & & $1.57(0.89-2.76)$ & \\
\hline Middle & $1.48(0.99-8.87)$ & & $1.91(1.06-3.46)$ & \\
\hline Richer & $1.46(0.96-2.23)$ & & $1.36(0.71-2.63)$ & \\
\hline Richest & $1.54(0.98-2.39)$ & & $1.85(0.89-3.84)$ & \\
\hline \multicolumn{5}{|l|}{ Working } \\
\hline No & 1 & $<0.001$ & 1 & 0.352 \\
\hline Yes & $2.02(1.56-2.62)$ & & $1.21(0.81-1.81)$ & \\
\hline Age at first birth & & 0.083 & & 0.046 \\
\hline $15-19$ & 1 & & 1 & \\
\hline Less than 15 & $1.73(0.93-3.19)$ & & $2.01(1.01-3.99)$ & \\
\hline
\end{tabular}

bold = Significant

Our study in comparison to other studies showed that contraceptive utilization in Uganda is lower than that of Kenya, Rwanda, Tanzania, Europe, Latin America and United States of America [1, 5, 16, 27-29] and higher than that in Nigeria [30]. The higher prevalence in Kenya can be attributed to the increased funding of policies and interventions being implemented by the Kenyan government compared to Uganda $[1,16]$. Compared to Uganda, Rwanda's small population size and the large population density might have contributed to the government's faster success in implementation of family planning programs $[1,31]$. Furthermore, use of government supported community health workers in providing short term methods in the community and the widely utilized community based health insurance program have increased accessibility to modern contraceptives [1, 16, 32, 33]. Although most young women in Kenya and Rwanda get their modern contraceptives from the free public sector facilities, most of the young women in Uganda access contraceptives from private sources with out-of-pocket expenditures [1, 2, 34]. This could as well contribute to the observed lower prevalence rate in Uganda. The modern contraceptive utilization rates in Europe and Latin America are approximately 50\% [28] and 30\% [5] respectively which are much higher than what we observed in our study. One of the reasons that can explain this is the higher gender equality in Europe which makes women empowered to make decisions regarding contraceptive use [28]. Another explanation could be the higher affluence in Europe compared to Uganda [28]. Adolescents 
belonging to affluent families could easily access contraceptives through private or public facilities.

The prevalence of contraceptive utilization among the adolescents in our study was lower than that in the older UDHS 2016 participants [22]. Furthermore, Li et al. analyzed 261 DHS and Multiple Cluster Indicator Surveys' datasets from 103 low- and middle-income countries between 2000 and 2017 showed that adult women aged 20 to 34 years had higher average contraceptive rate of $43.5 \%$ which is way higher compared to the finding in our study [35]. The lower utilization rate among adolescents could be attributed partly to the financial constraints of accessing the contraceptives, poor contraceptive knowledge, and limited availability of adolescent friendly health services [35].

Married adolescents were more likely to utilize modern contraceptives compared to unmarried adolescents. Married adolescents are more likely to afford contraceptives compared to their unmarried counterparts due to partner support [36]. Marital status has been shown to be associated with modern contraceptive use in other countries [36-38].Women whose age at first birth was less than 15 years were more likely to utilize modern contraceptives compared to those whose age at first birth was greater than 15 years. This might indicate improved health seeking behavioural which unfortunately comes in later after they have had a birth at a younger age [19]. Furthermore, adolescents that give birth at a younger age are more likely to utilize health facilities for antenatal care, delivery and post-natal care services [22] hence increased exposure to family planning counselling. Age at first birth has been shown to be associated with modern contraceptive utilization in similar studies [19, 39].

Adolescents belonging to the Central region were more likely to utilize modern contraceptives compared to those in the Northern region. The observed regional differences in utilization of modern contraceptives could be attributed to the differences in access to modern contraceptives, sociocultural contexts and job opportunities available to adolescents in the different regions [40]. Most of the young women in Uganda access contraceptives from private sources with out-of-pocket expenditures $[1,2]$. Central region unlike the Northern region is the central business region and home to the capital city hence more economically developed with a higher concentration of health facilities, economic opportunities and access to SRH mass communication means such as radios, newspapers [41-43]. All these factors enable easier access and affordability of modern contraceptives and also increase the probability of access to family planning information. Regional differences have similarly been shown to be associated with contraceptive use in various studies [19, 44-46].
Adolescents belonging to the poorest wealth quintile were less likely to utilize modern contraceptive methods compared to those belonging to the middle wealth quintile. Most of the young women in Uganda access contraceptives from private sources with out-of-pocket expenditures $[1,2,34]$. Hence the poor are more likely to have limited access to modern contraceptives due to the out of pocket expenditures to purchase the contraceptives or transport expenditures to free public health facilities $[19,47]$. The poor are less likely to be well informed about family planning which can be attributed to the low education levels, less likelihood to own radios, television sets, mobile phones or buy newspapers which limits the likelihood of getting family planning information to enable them make informed healthy choices [39, 48-50]. Wealth has been shown to be associated with modern contraceptive use in other studies $[19,49,51]$.

\section{Strengths}

We used a nationally representative sample and weighed the data for analysis and therefore our results are generalized to all Ugandan female adolescents aged 15 to 19 years. Standardised procedures are a requirement of DHS surveys in data collection and validated questionnaires are used which ensures the internal and external validity of the results.

\section{Limitations}

The cross-sectional design is limited by lack of temporality hence causality inferences cannot be made. Most data on the predictors were based on self-reporting and could not be verified through records and hence a possibility of information bias. Data on adolescents below 15 years was not available.

\section{Conclusion}

The findings of this study highlight the influence of age at first birth, region, wealth index and marital status as key predictors of contraceptive use among female adolescents in Uganda. The findings further show a need to promote the availability, accessibility and acceptability of modern contraceptives among female adolescents, especially those that reside in the rural areas who are likely to be poorer. Different stakeholders should design targeted and peer mediated interventions due to differences in adolescents according to their wealth index, regions and marital status.

\section{Supplementary Information}

The online version contains supplementary material available at https://doi. org/10.1186/s12905-021-01206-7.

Additional file 1: Table1. Independentvariables' categorization. 


\section{Abbreviations}

AOR: Adjusted odds ratio; Cl: Confidence interval; COR: Crude odds ratio; DHS: Demographic Health Survey; UDHS: Uganda Demographic Health Survey; OR: Odds ratio; SD: Standard deviation; WHO: World Health Organization; SPSS: Statistical Package for Social Science; USAID: United States Agency for International Development.

\section{Acknowledgements}

We thank the MEASURE DHS program for availing us with the data.

\section{Authors' contributions}

QS Conceived the idea, drafted the manuscript, performed analysis and interpreted the results. DM participated in the design of the study and helped in results interpretation and writing. MWM reviewed the first draft and drafted the subsequent versions of the manuscript. All authors read and approved the final manuscript.

\section{Funding}

No funding was obtained for this study.

\section{Availability of data and materials}

The data set used is openly available upon permission from MEASURE DHS website (URL: https://www.dhsprogram.com/data/available-datasets.cfm).

\section{Ethics approval and consent to participate}

High international ethical standards are ensured for MEASURE DHS surveys as ethical approval from the country is obtained from a national ethical review board (Uganda National Council for Science and Technology) and local authorities before implementing the survey and well-informed verbal consent is sought from the respondents prior to data collection [22, 52]. All methods of data collection were performed in accordance with the relevant guidelines and regulations. This data set was obtained from the MEASURE DHS website (URL: https://www.dhsprogram.com/data/available-datasets.cfm) after getting their permission and no formal ethical clearance was obtained since we conducted secondary analysis of publicly available data.

\section{Consent for publication}

Not applicable.

\section{Competing interests}

All authors declare that they have no competing interests.

\section{Author details}

${ }^{1}$ Monitoring and Evaluation Department, Doctors With Africa, CUAMM, TM Lion Hotel, Juba, South Sudan. ${ }^{2}$ Department of Obstetrics and Gynaecology, Busitema University, Tororo, Uganda. ${ }^{3}$ Department of Public Health, Busitema University, Tororo, Uganda. ${ }^{4}$ Sanyu Africa Research Institute, Mbale, Uganda.

Received: 9 November 2020 Accepted: 31 January 2021

Published online: 10 February 2021

\section{References}

1. Dennis ML, Radovich E, Wong KLM, Owolabi O, Cavallaro FL, Mbizvo MT, Binagwaho A, Waiswa P, Lynch CA, Benova L. Pathways to increased coverage: an analysis of time trends in contraceptive need and use among adolescents and young women in Kenya, Rwanda, Tanzania, and Uganda. Reproductive Health. 2017;14(1):130.

2. Campbell OM, Benova L, Macleod D, Goodman C, Footman K, Pereira AL, Lynch CA. Who, What, Where: an analysis of private sector family planning provision in 57 low- and middle-income countries. Tropical Med Int Health :TM \& IH. 2015;20(12):1639-56.

3. Casey SE, Gallagher MC, Kakesa J, Kalyanpur A, Muselemu J-B, Rafanoharana RV, Spilotros N. Contraceptive use among adolescent and young women in North and South Kivu, Democratic Republic of the Congo: a cross-sectional population-based survey. PLoS Med. 2020;17(3):e1003086.

4. Woog V, Singh S, Browne A, Philbin J. Adolescent Women's need for and use of sexual and reproductive health Services in Developing Countries. New York: Guttmacher Institute; 2015
5. de Vargas Nunes Coll C, Ewerling F, Hellwig F, de Barros AJD: Contraception in adolescence: the influence of parity and marital status on contraceptive use in 73 low-and middle-income countries. Reproductive Health 2019, 16(1):21.

6. WHO. Global Accelerated Action for the Health of Adolescents (AA-HA!): guidance to support country implementation. Geneva: World Health Organization; 2017.

7. Patton GC, Sawyer SM, Santelli JS, Ross DA, Afifi R, Allen NB, et al. Our future: a Lancet commission on adolescent health and wellbeing. Lancet. 2016;387(10036):2423-78. https://doi.org/10.1016/S0140-6736(16)00579 $-1$.

8. Paranjothy S, Broughton H, Adappa R, Fone D. Teenage pregnancy: who suffers? Arch Dis Child. 2009;94(3):239-45.

9. Conde-Agudelo A, Belizán JM, Lammers C. Maternal-perinatal morbidity and mortality associated with adolescent pregnancy in Latin America: cross-sectional study. Am J Obstet Gynecol. 2005;192(2):342-9.

10. de Vienne CM, Creveuil C, Dreyfus M. Does young maternal age increase the risk of adverse obstetric, fetal and neonatal outcomes: a cohort study. Eur J Obstet Gynecol Reprod Biol. 2009;147(2):151-6.

11. Chandra-Mouli V, Parameshwar PS, Parry M, et al. A never-before opportunity to strengthen investment and action on adolescent contraception, and what we must do to make full use of it. Reprod Health. 2017;14(1):85.

12. Population Reference Bureau. The faces of unmet need for family planning. Washington: PRB; 2012 [Available from: https://www.prb.org/faces -unmet-need-familyplanning/].

13. Namasivayam A, Lovell S, Namutamba S, Schluter PJ. Improved contraceptive use among women and men in Uganda between 1995-2016: a repeated cross-sectional population study. PLOS ONE. 2019;14(7):e0219963-e0219963.

14. Guttmacher Institute. Adding it up: investing in contraception and maternal and newborn health, 2017. New York: Guttmacher Institute; 2017 [Available from: https://www.guttmacher.org/fact-sheet/addingitup-contraception-mnh-2017]. .

15. MacQuarrie K. Unmet need for family planning among young women: levels and trends. . Rockville, Maryland. In: USA: ICF international; 2014.

16. Izugbara CO, Wekesah FM, Tilahun T, Amo-Adjei J, Tsala Dimbuene ZT. Family planning in East Africa: trends and dynamics. Nairobi, Kenya: African Population and Health Research Center (APHRC); 2018.

17. Asiimwe JB, Ndugga P, Mushomi J, Manyenye Ntozi JP. Factors associated with modern contraceptive use among young and older women in Uganda; a comparative analysis. BMC Public Health. 2014;14:926-926.

18. Kemigisha E, Bruce K, Nyakato VN, Ruzaaza GN, Ninsiima AB, Mlahagwa W, Leye $\mathrm{E}$, Coene G, Michielsen K. Sexual health of very young adolescents in South Western Uganda: a cross-sectional assessment of sexual knowledge and behavior. Reproductive Health. 2018;15(1):148.

19. Kabagenyi A, Habaasa G, Rutaremwa G. Low contraceptive use among young females in Uganda: does birth history and age at birth have an influence? Analysis of 2011 Demographic and Health Survey. J Contracept Stud. 2016;1(1):4

20. Stanback J, Mbonye AK, Bekiita M. Contraceptive injections by community health workers in Uganda: a nonrandomized community trial. Bull World Health Organ. 2007; 85(10):768-73. https://doi.org/https://doi. org/10.2471/BLT.07.040162.

21. Amugsi DA, Dimbuene ZT, Mberu B, Muthuri S, Ezeh AC. Prevalence and time trends in overweight and obesity among urban women: an analysis of demographic and health surveys data from 24 African countries, 1991-2014. BMJ open. 2017;7(10):e017344.

22. Uganda Bureau of Statistics - UBOS, ICF: Uganda Demographic and Health Survey 2016. In. Kampala, Uganda: UBOS and ICF; 2018.

23. Sserwanja Q, Mukunya D, Habumugisha T, Mutisya LM, Tuke R, Olal E. Factors associated with undernutrition among 20 to 49 year old women in Uganda: a secondary analysis of the Uganda demographic health survey 2016. BMC Public Health. 2020;20(1):1644.

24. Abrha S, Shiferaw S, Ahmed KY. Overweight and obesity and its sociodemographic correlates among urban Ethiopian women: evidence from the 2011 EDHS. BMC Public Health. 2016;16:636.

25. Dankwah E, Zeng W, Feng C, Kirychuk S, Farag M. The social determinants of health facility delivery in Ghana. Reproductive Health. 2019;16(1):101.

26. WHO.SDG 3: Ensure healthy lives and promote wellbeing for all at all ages.https://www.who.int/sdg/targets/en/. 
27. Guttmacher Institute: Adding It Up: Investing in Contraception and Maternal and Newborn Health for Adolescents in Kenya, 2018: https:// www.guttmacher.org/fact-sheet/adding-it-up-contraception-mnh-adole scents-kenya.

28. de Looze M, Madkour AS, Huijts T, Moreau N, Currie C. Country-level gender equality and adolescents' contraceptive Use in Europe, Canada and Israel: Findings from 33 Countries. Perspect Sex Reprod Health. 2019;51(1):43-53.

29. Scott RH, Wellings K, Lindberg L: Adolescent sexual activity, contraceptive use, and pregnancy in Britain and the U.S.: a multidecade comparison. J Adolescent Health 2020, 66(5):582-588.

30. Alayande A, Bello-Garko B, Umeh G and Nuhu I. Access to contraceptives for adolescents in northern Nigeria: a cross-sectional study from three secondary health facilities in Kaduna metropolis, Kaduna [version 1; peer review: 1 approved with reservations]. Gates Open Res 2019, 3:1476 (https://doi.org/https://doi.org/10.12688/gatesopenres.12968.1)

31. World Population Prospects, the 2015 Revision [https://esa.un.org/unpd/ wpp/Download/Standard/Population/].

32. Wesson J, Munyambanza E, Habrugira H, Nyinawamahoro A, Nzeyimana A, Mugeni C, Ngabo F: Introducing community-based provision of family planning Services in Rwanda: a process evaluation of the first six months of implementation. 2011.

33. Lu C, Chin B, Lewandowski JL, Basinga P, Hirschhorn LR, Hill K, Murray M, Binagwaho A. Towards universal health coverage: an evaluation of Rwanda Mutuelles in its first eight years. PLoS ONE. 2012;7(6):e39282.

34. Montagu D, Goodman C. Prohibit, constrain, encourage, or purchase: how should we engage with the private health-care sector? Lancet. 2016;6736:1-9.

35. Li Z, Patton G, Sabet F, Zhou Z, Subramanian SV, Lu C. contraceptive use in adolescent girls and adult women in low- and middle-income countries. JAMA Netw Open. 2020;3(2):e1921437-e1921437.

36. Nyarko SH. Prevalence and correlates of contraceptive use among female adolescents in Ghana. BMC Women's Health. 2015;15(1):60.

37. Durowade KA, Omokanye LO, Elegbede OE, Adetokunbo S, Olomofe CO, Ajiboye AD, Adeniyi MA, Sanni TA. Barriers to contraceptive uptake among women of reproductive age in a semi-urban community of Ekiti State, Southwest Nigeria. Ethiopian J Health Sci. 2017;27(2):121-8.

38. Appiah F, Seidu A-A, Ahinkorah BO, Baatiema L, Ameyaw EK. Trends and determinants of contraceptive use among female adolescents in Ghana: Analysis of 2003-2014 Demographic and Health Surveys. SSM - Population Health. 2020;10:100554-100554.

39. Bardaweel SK, Akour AA, Alkhawaldeh A. Impediments to use of oral contraceptives among refugee women in camps, Jordan. Women Health. 2019;59(3):252-65.

40. Rutaremwa G, Wandera SO, Jhamba T, Akiror E, Kiconco A. Determinants of maternal health services utilization in Uganda. BMC Health Serv Res. 2015;15:271.
41. Bbaale E, Guloba A. Maternal education and childbirth care in Uganda. Australasian Med J. 2011;4(7):389-99.

42. Jonathan D. Moyer, Mickey Rafa, Paul Sutton, Xuantong Wang. 2017. "Estimating District GDP in Uganda" Invited Research Paper for USAID. The Frederick S. Pardee Center for International Futures, University of Denver, Denver, CO. https://pardee.du.edu/estimating-district-gdp-uganda.

43. Mukwaya PI, Sengendo H, Lwasa S. Urban development transitions and their implications for poverty reduction and policy planning in Uganda. Urban Forum. 2010;21(3):267-81.

44. Asresie MB, Fekadu GA, Dagnew GW. Contraceptive use among women with no fertility intention in Ethiopia. PLoS ONE. 2020;15(6):e0234474.

45. Kungu W, Agwanda A, Khasakhala A: Trends and determinants of contraceptive method choice among women aged 15-24 years in Kenya [version 1; peer review: 1 approved with reservations]. F1000Research 2020, 9(197).

46. Mahmud M, Islam MM. Adolescent contraceptive use and its determinants in Bangladesh: evidence from Bangladesh Fertility Survey 1989. Contraception. 1995;52(3):181-6.

47. Prata N. Making family planning accessible in resource-poor settings. Philos Trans R Soc Lond B Biol Sci. 2009;364(1532):3093-9.

48. Rios-Zertuche D, Blanco LC, Zúñiga-Brenes P, Palmisano EB, Colombara DV, Mokdad AH, Iriarte E. Contraceptive knowledge and use among women living in the poorest areas of five Mesoamerican countries. Contraception. 2017;95(6):549-57.

49. Kumar M, Meena J, Sharma S, Poddar A, Dhalliwal V, Modi-Satish Chander Modi SC, Singh K. contraceptive use among low-income Urban married women in India. J Sex Med. 2011;8(2):376-82.

50. Bardaweel SK, Akour AAM-VZ, Kilani. Current knowledge, attitude, and patterns of oral contraceptives utilization among women in Jordan. BMC Women's Health. 2015;15(1):117.

51. Tekelab T, Melka AS, Wirtu D. Predictors of modern contraceptive methods use among married women of reproductive age groups in Western Ethiopia: a community based cross-sectional study. BMC Women's Health. 2015;15(1):52.

52. Rutstein SO, Staveteig S: Making the Demographic and Health Surveys Wealth Index comparable. In: DHS Methodological Reports No 9. Rockville, Maryland, USA: ICF International; 2014.

\section{Publisher's Note}

Springer Nature remains neutral with regard to jurisdictional claims in published maps and institutional affiliations.

Ready to submit your research? Choose BMC and benefit from:

- fast, convenient online submission

- thorough peer review by experienced researchers in your field

- rapid publication on acceptance

- support for research data, including large and complex data types

- gold Open Access which fosters wider collaboration and increased citations

- maximum visibility for your research: over 100M website views per year

At BMC, research is always in progress.

Learn more biomedcentral.com/submissions 